\title{
Worst Case Error Budget and Analysis in the Design of a Novel Signal Conditioning Circuit for Eddy Current Flow Meter in Sodium Cooled Fast Breeder Reactor
}

\author{
Poornapushpakala Suriyamoorthi ${ }^{* *}$ and Gomathy Chidambaram² \\ ${ }^{1}$ Research Scholar, Department of E\&CE, Sathyabama University, Chennai-600 119, India; \\ poornapushpakalas@gmail.com \\ 2 Professor \& Head, Department of ECE, SRM University, Vadapalani, Chennai, India; s_ppk@rediffmail.com
}

\begin{abstract}
This paper attempts to describe the worst case error budget and analysis of a novel signal conditioning circuit which is an integral part a measuring electronics developed for the measurement of sodium flow from eddy current flow meter. The flow sensor is fitted in the sodium cooled fast breeder reactor for measuring sodium flow in the outlet of the primary sodium pump and fuel subassemblies at Indira Gandhi Centre for Atomic Research, Kalpakkam, India. It is essential to calculate the error budget and perform the error analysis to evaluate the reliability of the signal conditioning circuit. The work focuses on calculating the error in the circuit, which will affect the absolute accuracy, resolution and drift in the measurement. Based on the specification of each component in the circuit, the worst case error budget and analysis is done. This enables to design a circuit that produce less error even when operated in the worst possible conditions by making comparison of all possible component errors.
\end{abstract}

Keywords: Error Analysis, Error Budget, Worst Case, Circuit, Signal Conditioning.

\section{Introduction}

A reliable hardware could be built by accounting all component tolerances during the design stage. Worst Case Design becomes complicated because active and passive components have different error sources and tolerances [1]. Worst Case Circuit Analysis (WCCA) is a technique which, by accounting for component variability, determines circuit performance under a worst case scenario like extreme environmental or operating conditions. Environmental Conditions which include external stress, like temperature, humidity or radiation, are applied to each circuit component and Operating Conditions include external electrical inputs which affect component quality level, interaction between parts, and drift due to component aging [2]. WCCA allows an assessment of actual applied part stress against rated part parameters which enables us to verify that the components will function properly under all conditions [3]. Worst case performance is determined by analytically selecting the worst combination of conditions that the design can experience during its operational lifetime [4]. Worst case analysis can be done using Extreme Value Analysis, Root Sum Squared and Monte-Carlo Analysis [5]. This paper deals with the computation of worst case error budget and analysis using extreme value analysis in the design of a novel signal conditioning circuit.

*Corresponding author:

Poornapushpakala Suriyamoorthi (poornapushpakalas@gmail.com) 


\section{Description of Eddy Current Flow Meter}

Sodium is the main coolant in fast breeder nuclear reactor. Monitoring the flow of sodium to the fuel subassemblies is essential in order to prevent the nuclear reactor from nuclear meltdown. The Eddy Current Flow Meter (ECFM) is a flow sensor which is fitted at the outlet of the primary sodium pump. ECFM consists of one primary and two secondary coils placed symmetrically one in upstream side and other in downstream side of primary. The primary coil is excited by a constant current of $200 \mathrm{~mA}$ with a frequency of $400 \mathrm{~Hz}$ [6-9]. ECFM works on the principle of change in the magnetic field due to induced eddy currents as a result of sodium flow [10-12]. If the primary excited ECFM is placed in flowing sodium, then voltage is induced in both the secondary due to motion of the flowing sodium in addition to the transformer voltage. The outputs of the ECFM secondary signals are sinusoidal in nature at a frequency of excitation $(400 \mathrm{~Hz})$. A measuring electronics is developed for monitoring the changes in the sodium flow at a faster rate. This electronics has a signal conditioning unit, Programmable System on Chip (PSoC) microcontroller unit and display unit in addition to a graphical monitoring system $[13,14]$. Figure 1 shows the Block Diagram representation of the developed fast response system for ECFM.

\section{Signal Conditioning Circuit}

The ECFM secondary coils produce output in the range of 0 to $100 \mathrm{mV}$ corresponding to a Sodium flowrate of 0 to $30 \mathrm{~m}^{3} / \mathrm{hr}$. Since the signal is very meager, instrumentation amplifier is used for eliminating noise. For ensuring the safety of the electronics from the sensor unit, isolation amplifier should be included in the design. A band pass

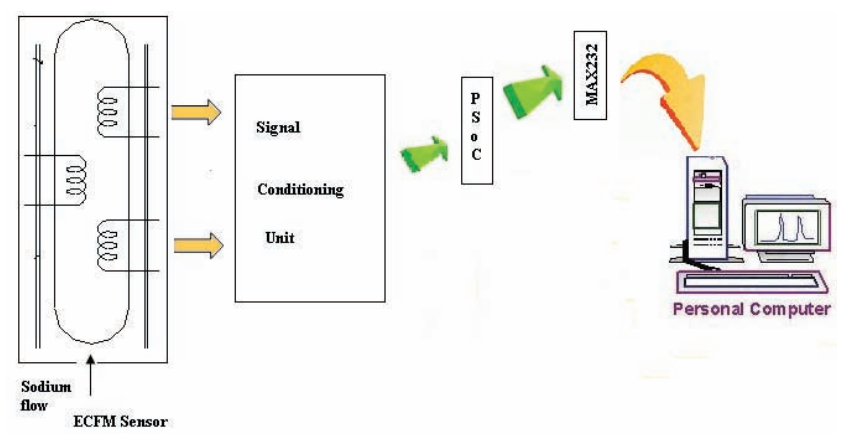

Figure 1. Schematic representation of fast response electronics. filter is used to select only the signal and rejects all other noise frequency components. A True RMS to DC converter is implemented in the circuit for conversion of $\mathrm{AC}$ to DC signal for further processing with microcontroller. Microcontroller acquires the signal from the signal conditioning circuit and process the signal for computing sodium velocity. Figure 2 shows the block diagram representation of the signal conditioning circuit. The next section deals with the computation of error for various components and the comparison with respect to the error.

\section{Error Budget and Analysis}

The absolute accuracy of the measurement electronics is affected by characteristics like input offset voltage, output offset voltage, input offset current, CMRR and gains [15]. There will be drift in measurement due to change in the operating temperature. The temperature has effect on the characteristics like gain, input offset voltage, input offset current and output offset voltage. Similarly the resolution is affected by the characteristics like gain non-linearity and voltage noise [16].

From the specification the maximum or typical error due to the parameter is taken into consideration. For each stage the input resistance $\left(\mathrm{R}_{\text {in }}\right)$ and Full Scale Range (FSR) of the input varies based on the design requirement of the circuit. FSR of $100 \mathrm{mV}, \mathrm{R}_{\text {in }}$ is $100 \Omega$ and gain of 11 is considered for the error computation at the first stage for instrumentation amplifier. For the remaining stages the FSR is $1 \mathrm{~V}$, unity gain is considered for error computation. All error should be computed based on a common dimensionless unit i.e parts per million (ppm) $[17,18]$. The error affecting the absolute accuracy is computed based on equation (1-3).

$$
\text { Offset Voltage Error }=\frac{\text { Error Specification } \times 10^{6}}{\text { Input FSR }} \mathrm{inppm}
$$

$$
\begin{aligned}
& \text { Offset Current Error }= \\
& \frac{\text { Error Specification } \times \text { Input resistance } \times 10^{6}}{\text { Input FSR }} \text { in ppm }
\end{aligned}
$$

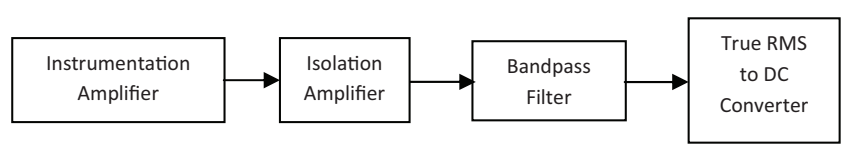

Figure 2. Block diagram of signal conditioning circuit. 


$$
\text { Gain Error }=\text { Error Specification } \times 10^{6} \text { in } \mathrm{ppm}
$$

Drift due to temperature is calculated based on the accuracy at operating temperature of $25^{\circ} \mathrm{C}$ in the specification for that component and how much is the drift from the actual operating condition of the application. An operating temperature of $85^{\circ} \mathrm{C}$ is considered for the calculation hence a deviation of $60^{\circ} \mathrm{C}$ is considered for the computation of error. The error due to temperature is computed based on the equation (4-6). The error due to the passive components in the circuit is computed based on the equation $(7,8)$

$$
\begin{aligned}
& \text { Offset Voltage Error }= \\
& \frac{\text { Error Specification } \times \text { Drift in temperature } 10^{6}}{\text { Input FSR }} \text { in ppm }
\end{aligned}
$$

$$
\begin{aligned}
& \text { Offset Current Error }= \\
& \text { Error Specification } \times \text { Input resistance } \times \\
& \frac{\text { Drift in temperature } \times 10^{6}}{\text { Input FSR }}
\end{aligned}
$$

Gain Error $=$ Error Specification $\times$ Drift in temperature $\times 10^{6}$ in ppm

Error due to resistors in the circuit $=$

Number of resistors $\times \%$ tolerance for single resistor

Error due to capacitors in the circuit $=$ Number of capacitors $\times \%$ tolerance for single capacitor

\section{Result and Discussion}

Table 1 shows the error due to INA128 IC, which has less influence on the absolute accuracy and resolution of the circuit. Table 2 depicts that though resolution error is same for AD215 and ISO120, the error affecting the absolute accuracy is more in case of AD215. Table 3 shows drift in temperature produces minimal change in the characteristics of UAF42 IC than other filter ICs. Only bandpass filter ICs were considered for this computation. From Table 4 it is clear that for true RMS to DC converters, AD736 is the least error producing IC. Hence the novel signal conditioning circuit is designed with the INA128, ISO120, UAF42 and AD736 ICs. Figure 3 shows the design of signal conditioning circuit. The overall unadjusted error of the active components in a signal conditioning circuit was found to be $2.088 \%$. Overall resolution error due to the components is found to be $0.0054 \%$. The overall error for worst case conditions including all the passive components in the circuit is calculated to be $2.168 \%$.

\section{Conclusion}

The Error Budget Analysis of various components was done and the Signal Conditioning Circuit was designed with the components that give less error when operated under worst case conditions. Error analysis with Pspice Software could be done for various conditions and for different part parameter. Design of the circuit can be done with the comparison of Worst Case Analysis and Monte Carlo Analysis. The unadjusted errors can be corrected in the design by considering the worst case scenario but resolution error cannot be adjusted.

\section{Acknowledgement}

This work was supported by Indira Gandhi Centre for Atomic Research, Department of Atomic Energy, Kalpakkam, India. The authors are much thankful to all the scientists and the Director of IGCAR, Kalpakkam.

\section{References}

1. Ashcraft W D, and Hochwald W (1961). Design by worstcase analysis: a systematic method to approach specified reliability requirements, IRE Transactions on Reliability and Quality Control, vol RQC-10(3), 15-21.

2. Nassif S R, and Strojwas A J (1986). A methodology for worst-case analysis of integrated circuits, IEEE Transactions on Computer-Aided Design of Integrated Circuits and Systems, vol 5(1), 104-113.

3. Mohan M N, and Kumar J V (2007). Novel signal conditioning circuit for push-pull type capacitive transducers, IEEE Transaction on Instrumentation and Measurement, vol 56(1), 153-157.

4. Mancini R (2002). Worst-case design of op amp circuits, Analog Applications Journal, vol 2Q, 42-46.

5. Kendall P E R. Reduce technical risk and improve system reliability, Intuitive Research and Technology Corporation, 1-9.

6. Veerasamy R, Asokane C et al. (2001). Eddy current flowmeter for incore flow measurement in fast reactors. 8th National Seminar on Physics Technology of Sensors (NSTPS-8) in Feb 2001 at IGCAR, Kalpakkam. 


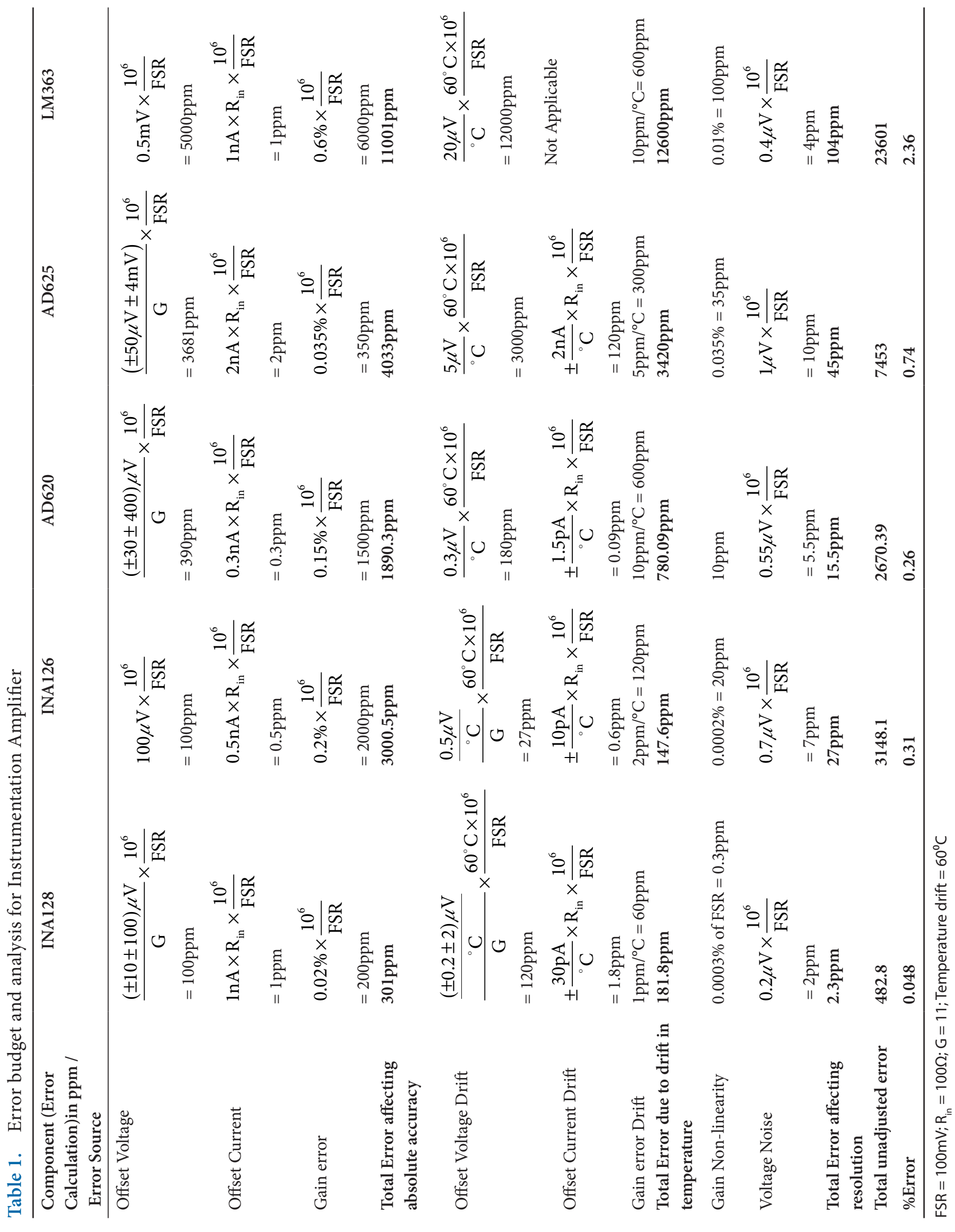


Table 2. Error budget and analysis for Isolation Amplifier

\begin{tabular}{|c|c|c|c|}
\hline $\begin{array}{l}\text { Component (Error Calculation)in ppm / } \\
\text { Error Source }\end{array}$ & ISO120 & $\mathrm{AD} 215$ & ISO122 \\
\hline Offset Voltage & $\begin{array}{l} \pm 5 \mathrm{mV} \times \frac{10^{6}}{\mathrm{FSR}} \\
=5000 \mathrm{ppm}\end{array}$ & $\begin{array}{l}( \pm 0.4 \pm 35) \mathrm{mV} \times \frac{10^{6}}{\text { FSR }} \\
=34400 \mathrm{ppm}\end{array}$ & $\begin{array}{l} \pm 20 \mathrm{mV} \times \frac{10^{6}}{\mathrm{FSR}} \\
=20000 \mathrm{ppm}\end{array}$ \\
\hline Gain error & $\begin{array}{l}0.04 \% \text { of FSR } \\
=400 \mathrm{ppm}\end{array}$ & $\begin{array}{l}0.5 \% \\
=5000 \mathrm{ppm}\end{array}$ & $\begin{array}{l}0.05 \% \text { of FSR } \\
=500 \mathrm{ppm}\end{array}$ \\
\hline Total Error affecting absolute accuracy & $5400 \mathrm{ppm}$ & $39400 \mathrm{ppm}$ & 20500ppm \\
\hline Offset Voltage Drift & $\begin{array}{l}\frac{100 \mu \mathrm{V}}{{ }^{\circ} \mathrm{C}} \times \frac{60^{\circ} \mathrm{C} \times 10^{6}}{\mathrm{FSR}} \\
=6000 \mathrm{ppm}\end{array}$ & $\begin{array}{l}\frac{( \pm 2 \pm 30) \mu \mathrm{V}}{{ }^{\circ} \mathrm{C}} \times \frac{60^{\circ} \mathrm{C} \times 10^{6}}{\mathrm{FSR}} \\
=1920 \mathrm{ppm}\end{array}$ & $\begin{array}{l}\frac{200 \mu \mathrm{V}}{{ }^{\circ} \mathrm{C}} \times \frac{60^{\circ} \mathrm{C} \times 10^{6}}{\mathrm{FSR}} \\
=12000 \mathrm{ppm}\end{array}$ \\
\hline Gain error Drift & $5 \mathrm{ppm} /{ }^{\circ} \mathrm{C}=300 \mathrm{ppm}$ & $15 \mathrm{ppm} /{ }^{\circ} \mathrm{C}=900 \mathrm{ppm}$ & $10 \mathrm{ppm} /{ }^{\circ} \mathrm{C}=600 \mathrm{ppm}$ \\
\hline Total Error due to drift in temperature & $6300 \mathrm{ppm}$ & $2820 \mathrm{ppm}$ & 12600ppm \\
\hline Gain Non-linearity & $0.005 \%$ of FSR $=50 \mathrm{ppm}$ & $0.005 \% 50 \mathrm{ppm}$ & of FSR $=160 \mathrm{ppm}$ \\
\hline Total Error affecting resolution & $50 \mathrm{ppm}$ & $50 \mathrm{ppm}$ & $160 \mathrm{ppm}$ \\
\hline Total unadjusted error & 11700 & 42220 & 33100 \\
\hline \%Error & 1.17 & 4.22 & 3.31 \\
\hline
\end{tabular}

$\mathrm{FSR}=1 \mathrm{~V} ; \mathrm{G}=1 ;$ Temperature drift $=60^{\circ} \mathrm{C}$

Table 3. Error budget and analysis for Active Bandpass Filter

\begin{tabular}{llll}
\hline $\begin{array}{l}\text { Component (Error Calculation)in ppm / } \\
\text { Error Source }\end{array}$ & \multicolumn{1}{c}{ MAX267 } & \multicolumn{1}{c}{ UAF42 } & \multicolumn{1}{c}{ LT1568 } \\
\hline Offset Voltage & $\pm 0.05 \mathrm{~V} \times \frac{10^{6}}{\mathrm{FSR}}$ & $\pm 5 \mathrm{mV} \times \frac{10^{6}}{\mathrm{FSR}}$ & $( \pm 5.2 \pm 4) \mathrm{mV} \times \frac{10^{6}}{\mathrm{FSR}}$ \\
& $=50000 \mathrm{ppm}$ & $=5000 \mathrm{ppm}$ & $=5200 \mathrm{ppm}$ \\
Error affecting absolute accuracy & $50000 \mathrm{ppm}$ & $5000 \mathrm{ppm}$ & $5200 \mathrm{ppm}$ \\
Offset Voltage Drift & $\frac{0.75 \mathrm{mV}}{{ }^{\circ} \mathrm{C}} \times \frac{60^{\circ} \mathrm{C} \times 10^{6}}{\mathrm{FSR}}$ & $\pm \frac{3 \mu \mathrm{V}}{{ }^{\circ} \mathrm{C}} \times \frac{60^{\circ} \mathrm{C} \times 10^{6}}{\mathrm{FSR}}$ & Not applicable \\
& $=45000 \mathrm{ppm}$ & $=180 \mathrm{ppm}$ & \\
Gain error Drift & $20 \mathrm{ppm} /{ }^{\circ} \mathrm{C}=1200 \mathrm{ppm}$ & Not applicable & Not applicable \\
Total Error due to drift in temperature & $46200 \mathrm{ppm}$ & $180 \mathrm{ppm}$ & - \\
Voltage Noise & $90 \mu \mathrm{V}=90 \mathrm{ppm}$ & $2 \mu \mathrm{V}=2 \mathrm{ppm}$ & - \\
Total Error affecting resolution & $90 \mathrm{ppm}$ & $2 \mathrm{ppm}$ & - \\
Total unadjusted error & $96200 \mathrm{ppm}$ & $5180 \mathrm{ppm}$ & $5200 \mathrm{ppm}$ \\
\%Error & 9.6 & 0.51 & 0.52 \\
\hline
\end{tabular}

$\mathrm{FSR}=1 \mathrm{~V} ; \mathrm{G}=1 ;$ Temperature drift $=60^{\circ} \mathrm{C}$ 
Table 4. Error budget and analysis for True RMS to DC Converter

\begin{tabular}{|c|c|c|c|c|}
\hline $\begin{array}{l}\text { Component (Error } \\
\text { Calculation)in ppm / } \\
\text { Error Source }\end{array}$ & AD736 & AD536 & LTC1966 & LH0091 \\
\hline Offset Voltage & $\begin{array}{l}( \pm 3 \pm 0.1) \mathrm{mV} \times \frac{10^{6}}{\mathrm{FSR}} \\
=3100 \mathrm{ppm}\end{array}$ & $\begin{array}{l}( \pm 2 \pm 2) \mathrm{mV} \times \frac{10^{6}}{\mathrm{FSR}} \\
=4000 \mathrm{ppm}\end{array}$ & $\begin{array}{l} \pm 20 \mathrm{mV} \times \frac{10^{6}}{\mathrm{FSR}} \\
=20000 \mathrm{ppm}\end{array}$ & - \\
\hline $\begin{array}{l}\text { Total Error affecting } \\
\text { absolute accuracy }\end{array}$ & $3100 \mathrm{ppm}$ & $4000 \mathrm{ppm}$ & 20000ppm & $\begin{array}{l}20 \mathrm{mV}, \pm 0.5 \% \\
=25000 \mathrm{ppm}\end{array}$ \\
\hline Offset Voltage Drift & $\begin{array}{l}\frac{( \pm 8 \pm 1) \mathrm{mV}}{{ }^{\circ} \mathrm{C}} \times \frac{60^{\circ} \mathrm{C} \times 10^{6}}{\mathrm{FSR}} \\
=540 \mathrm{ppm}\end{array}$ & $\begin{array}{l} \pm \frac{0.1 \mathrm{mV}}{{ }^{\circ} \mathrm{C}} \times \frac{60^{\circ} \mathrm{C} \times 10^{6}}{\mathrm{FSR}} \\
=6000 \mathrm{ppm}\end{array}$ & Not Applicable & - \\
\hline $\begin{array}{l}\text { Total Error due to drift in } \\
\text { temperature }\end{array}$ & $540 \mathrm{ppm}$ & $6000 \mathrm{ppm}$ & - & $\begin{array}{l}0.25 \mathrm{mV} /{ }^{\circ} \mathrm{C}, \pm 0.2 \% /{ }^{\circ} \mathrm{C} \\
=1,35,000 \mathrm{ppm}\end{array}$ \\
\hline Total unadjusted error & $3640 \mathrm{ppm}$ & $10000 \mathrm{ppm}$ & 20000ppm & $1,60,000 \mathrm{ppm}$ \\
\hline \%Error & 0.364 & 1 & 2 & 16 \\
\hline
\end{tabular}

FSR $=1 \mathrm{~V} ; \mathrm{G}=1 ;$ Temperature drift $=60^{\circ} \mathrm{C}$

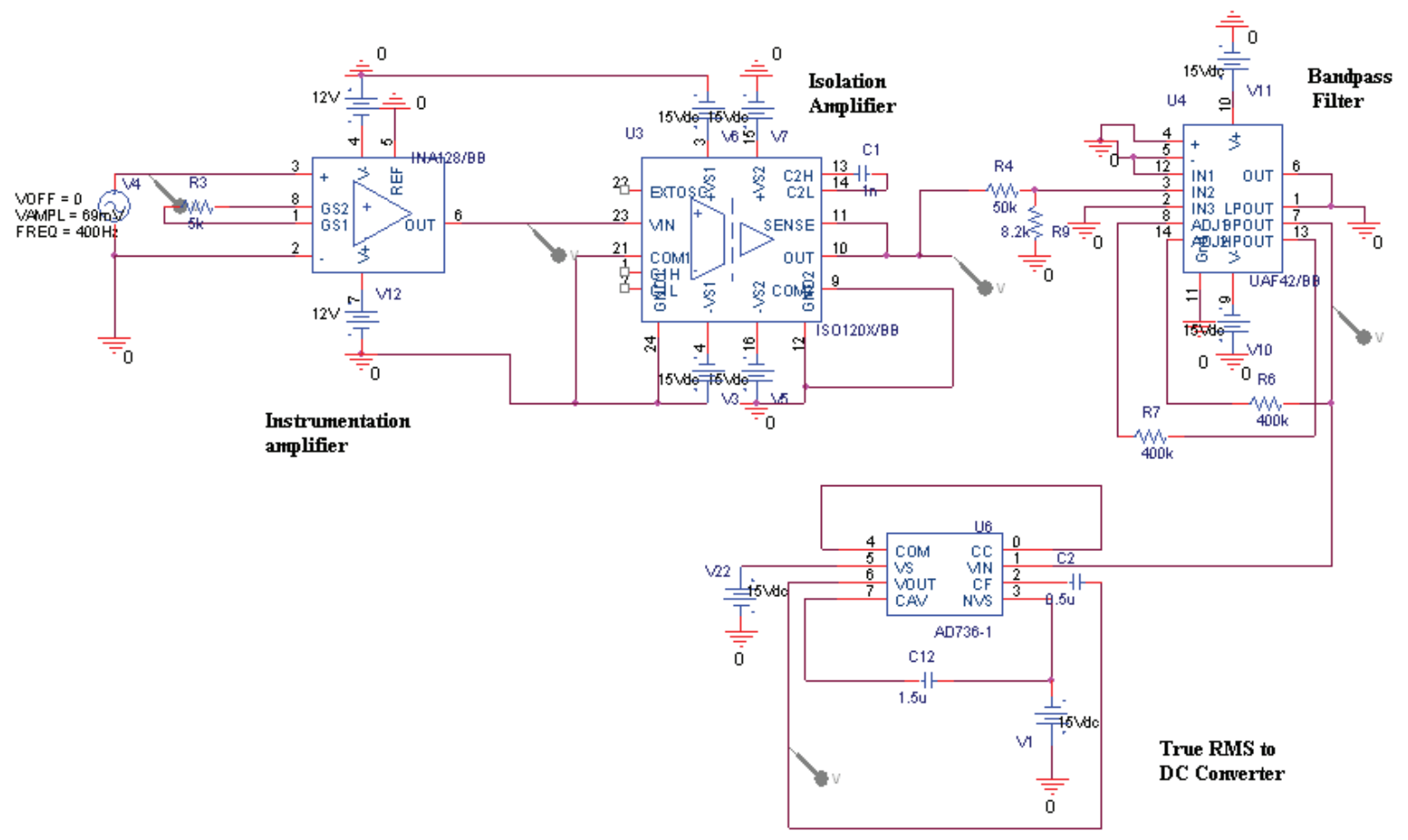

Figure 3. Design of signal conditioning circuit. 
7. Veerasamy R, Sureshkumar S et al. (2007). Eddy current flow sensor development and testing for LMFBR Sodium Pumps, 15th International Conference on Nuclear Engineering Nagoya, Japan.

8. Sharma P, Dash S K et al. (2009). Performance prediction of eddy current flowmeter for sodium, in Proceedings of the COMSOL Conference 2009, Bangalore.

9. Sharma P, Kumar S S et al. (2010). Development, computer simulation and performance testing in sodium of an eddy current flowmeter, Annals of Nuclear Energy, vol 37(3), 332-338, Available from: http://dx.doi.org/10.1016/j. anucene.2009.12.009

10. Wiegand D E (1968). Summary of an analysis of the eddy current flowmeter, IEEE Transaction on Nuclear Science, vol 15(1), 28-36, doi: 10.1109/TNS.1968.4324826.

11. Wiegand D E, and Michels C W (1969). Performance tests on an eddy-current flowmeter, IEEE Transactions on Nuclear Science, vol 16(1), 192-195, doi: 10.1109/ TNS.1969.4325106.

12. Poornapushpakala S, Gomathy C et al. (2010). Eddy current flowmeter - a review, Proceedings of the International Conference on Recent Advances in Space Technology
Services \& Climate Changes, 214-217, doi: 10.1109/ RSTSCC.2010.5712844.

13. Poornapushpakala S, Gomathy C et al. (2011). Design of fast response electronics for eddy current flowmeter, The Proceedings of 7 th International Conference on Trends in Industrial Measurements and Automation, 299-303.

14. Poornapushpakala S, and Gomathy C (2012). Design, development and performance analysis of signal conditioning circuit of fast response electronics for eddy current flowmeter in PFBR, International Journal on Intelligent Electronic Systems, vol 6(1), 24-30.

15. Nash E (1998). A practical review of common mode and instrumentation amplifiers, Sensors Magazine, vol 15(7), 26-33.

16. Zumbahlen H (2008). Linear Circuit Design Handbook, Chapter 1, 2, Newnes Publications, 1-185.

17. Jung W G (2005). Op Amp Applications Handbook, Chapter 1, 2, Newnes Publications, 3-161.

18. Kitchin C, and Counts L (2006). A Designer's Guide to Instrumentation Amplifiers, $3^{\text {rd }}$ Edn., Chapter 1, Analog Devices, 3-51. 